\title{
A breast reconstruction needs assessment: How does self-efficacy affect information access and preferences?
}

\author{
Andrea Lam MD (Candidate) ${ }^{1}$, Scott Secord MSW RSW2, Kate Butler MHSc ${ }^{3}$, Stefan OP Hofer MD PhD ${ }^{3,5}$ \\ Emily Liu BHS MD (Candidate) ${ }^{4}$, Kelly A Metcalfe RN PhD ${ }^{6}$, Toni Zhong MD MHS ${ }^{3,5}$
}

\begin{abstract}
A Lam, S Secord, K Butler, et al. A breast reconstruction needs assessment: How does self-efficacy affect information access and preferences? Can J Plast Surg 2012;20(1):37-42.
\end{abstract}

BACKGROUND: Breast cancer patients requiring mastectomy do not consistently receive information about post-mastectomy breast reconstruction (PMBR) surgery from the treatment team. Patients have varying levels of self-efficacy, defined as one's confidence in their ability to gather information and make health-related decisions. The present preliminary study was designed to evaluate the relationship between self-efficacy and access to PMBR information.

METHODS: A qualitative interview study was conducted on a convenience sample of 10 breast cancer patients considering or having already undergone PMBR and six key health care provider informants. The modified six-item Stanford Self-Efficacy Scale for managing chronic disease was administered.

RESULTS: Patient self-efficacy scores ranged from 5 to 9.3 (out of 10). Two main access to information themes were identified from the patient qualitative data: theme A - difficulty initiating the PMBR discussion; and theme $\mathrm{B}$ - perceived lack of access to PMBR information with the subthemes of timing, modality, quantity and content of resources. All respondents expressed their concern over the absence of a standardized process for initiating the dialogue of PMBR. Patients also reported that credible and easily accessible information was not routinely available and expressed a desire to hear about their PMBR options early in the decision-making process.

CONCLUSIONS: Health care providers may need to assume more responsibility in standardizing information dissemination on PMBR. This information should be distributed early in the consultation process, the content should be complete, and there may be a role for individualizing the delivery of information based on a patient's level of self-efficacy.

Key Words: Breast reconstruction; Information access and preferences; Selfefficacy; Qualitative

$\mathrm{R}$ ates of post-mastectomy breast reconstruction (PMBR) have been rising in the past decade because of increased public awareness and expanded acceptance of the oncological safety of this procedure. However, a recent survey of 762 breast cancer patients conducted by the Cancer Support Community (1) found that $43 \%$ of patients do not receive information about PMBR choices by the time they must make final breast cancer treatment decisions. Lack of access to information about PMBR makes it difficult for breast cancer patients to make informed, educated and personally satisfying decisions about whether to undergo reconstruction (1).

In addition to the issue of information availability, patients themselves have varying levels of knowledge-seeking and health-promoting behaviours. This character trait is known as self-efficacy, which is defined as one's confidence in his or her ability to take action (2). In today's health care model of patient-centred care, self-efficacy enables

\section{Une évaluation des besoins en reconstruction mammaire : comment l'autoefficacité influe-t-elle sur l'accès à l'information et sur les préférences ?}

\begin{abstract}
HISTORIQUE : Les patientes atteintes de cancer du sein qui ont besoin de subir une mastectomie ne reçoivent pas systématiquement de l'information sur la reconstruction mammaire après une opération (RMAO) de la part de l'équipe soignante. Les patients ont divers degrés d'autoefficacité, définie comme la confiance en leur habileté à recueillir de l'information et à prendre des décisions liées à leur santé. La présente étude préliminaire a été conçue pour évaluer la relation entre l'autoefficacité et l'accès à l'information sur la RMAO.

MÉTHODOLOGIE : Une étude d'entrevue qualitative a été menée sur un échantillon de commodité de dix patientes atteintes du cancer du sein qui envisageaient subir une RMAO ou l'avaient déjà subie et six informateurs qui étaient des professionnels de la santé. Les chercheurs ont administré l'échelle d'autoefficacité modifiée de Stanford en six éléments pour prendre en charge les maladies chroniques.

RÉSULTATS : Les indices d'autoefficacité variaient de 5 à 9,3 (sur 10). Les données qualitatives des patientes ont permis de repérer deux grands thèmes d'accès à l'information : thème $\mathrm{A}$ - difficulté à amorcer la discussion sur la RMAO; et thème $\mathrm{B}$ - absence perçue d'accès à l'information de la RMAO, ainsi que les sous-thèmes du moment, de la modalité, de la quantité et du contenu des ressources. Tous les répondants ont exprimé leur préoccupation quant à l'absence de processus standardisé pour amorcer le dialogue sur la RMAO. Les patients ont également déclaré qu'il n'était pas systématiquement possible d'obtenir de l'information crédible et facilement accessible et ont exprimé le souhait d'entendre parler des diverses possibilités de RMAO au début du processus de prise de décision.

CONCLUSIONS : Les dispensateurs de soins peuvent avoir besoin d'assumer plus de responsabilités dans la standardisation de la diffusion de l'information sur la RMAO. Il faudrait distribuer cette information rapidement dans le processus de consultation, le contenu devrait être complet, et il pourrait être bon de personnaliser la transmission de l'information d'après le taux d'autoefficacité du patient.
\end{abstract}

the patient to be more involved with the health care team and in the management of his/her condition (2). Through a cross-sectional survey of low-income women with newly diagnosed breast cancer, Maly et al (3) found that self-efficacy in the domain of patient-physician communication affected the rate of planned or completed breast reconstructive surgery. The authors concluded that empowering women by improving self-efficacy and patient-physician communication may help to overcome some of the barriers to accessing PMBR.

To better understand the complex relationship that may exist between self-efficacy and access to PMBR information, a qualitative study was conducted at the Breast Cancer Survivorship Program (BCSP) at a tertiary cancer centre. To the best of our knowledge, the relationship between self-efficacy and access to PMBR information has not been previously explored. Through the combined approach of semistructured qualitative interviews and quantitative assessment of

Gedicine, Universily of Toronto, Survivorship Program, Princess Margaret Hospital, University Health Network, Division of Plastic

$\mathcal{B}$ Reconstructive Surgery, Department of Surgery and Surgical Oncology, University Health Network, Toronto; ${ }^{4}$ Faculty of Medicine,

University of Western Ontario, London; ${ }^{5}$ Division of Plastic $\mathcal{E}$ Reconstructive Surgery, University of Toronto; ${ }^{6}$ Lawrence S Bloomberg Faculty of Nursing, University of Toronto, Toronto, Ontario

Correspondence: Dr Toni Zhong, The University Health Network Breast Restoration Unit, Division of Plastic and Reconstructive Surgery,

University Health Network, 8N 871, 200 Elizabeth Street, Toronto, Ontario M5G 2C4. Telephone 416-340-3858, fax 416-340-4403,

e-mail toni.zhong@uhn.on.ca 
TABLE 1

Demographic information and self-efficacy scores of participants

\begin{tabular}{|c|c|c|c|c|c|c|c|}
\hline \multirow{2}{*}{$\begin{array}{l}\text { Patient } \\
\text { number }\end{array}$} & \multirow{2}{*}{$\begin{array}{c}\text { Self-efficacy } \\
\text { score (out of } 10)^{*}\end{array}$} & \multirow{2}{*}{$\begin{array}{l}\text { Age, } \\
\text { years }\end{array}$} & \multirow{2}{*}{$\begin{array}{l}\text { Highest level of } \\
\text { education completed }\end{array}$} & \multirow{2}{*}{$\begin{array}{l}\text { Frequency of } \\
\text { financial difficulty }\end{array}$} & \multirow{2}{*}{$\begin{array}{l}\text { Time elapsed since } \\
\text { breast cancer diagnosis }\end{array}$} & \multicolumn{2}{|c|}{ Before or after } \\
\hline & & & & & & Mastectomy & PMBR \\
\hline 1 & 9.33 & 63 & Doctorate & Never & 9 years 5 months & Before & Before \\
\hline 2 & 8.83 & 41 & High school & Somewhat greater & 2 years 3 months & Before & Before \\
\hline 3 & 8.17 & 42 & Undergraduate & Never & 8 months & After & After \\
\hline 4 & 8.17 & 75 & Undergraduate & Never & 2 years 3 months & After & After \\
\hline 5 & 8.17 & 55 & Master's & Occasionally & 1 years 2 months & After & Before \\
\hline 6 & 7.83 & 52 & High school & Infrequently & 1 year 3 months & After & Before \\
\hline 7 & 7.83 & 46 & Undergraduate & Infrequently & 2 years 2 months & After & Before \\
\hline 8 & 6.50 & 44 & Undergraduate + professional degree & Occasionally & 1 year 7 months & After & After \\
\hline 9 & 5.33 & 48 & Undergraduate & Occasionally & 8 years & After & Before \\
\hline 10 & 5.00 & 29 & Master's & Never & 11 months & After & Before \\
\hline
\end{tabular}

${ }^{*} A$ higher score indicates greater self-efficacy. PMBR Post-mastectomy breast reconstruction

patients' self-efficacy levels using the modified Stanford Self-Efficacy Scale (4), we sought to identify a relationship between self-efficacy and access to PMBR information. Interviews with key health care informants were also conducted to identify any discrepancies between patients and members of the health care team with regard to perceived access to PMBR information. The present study is part of a larger project that aims to understand the effects of information access and selfefficacy on decision regret following PMBR.

\section{METHODS}

Study design and patient recruitment

Local institutional ethics review board approval was obtained before the study. Participants were recruited by convenience sampling at the BCSP, and at the plastic surgery clinic at Toronto General Hospital (Toronto, Ontario), from February 15 to April 15, 2010. Inclusion criteria included: patients with a diagnosis of breast cancer and who had undergone mastectomy; were either considering or had already completed PMBR; were older than 18 years of age; and were fluent in English.

\section{Questionnaires}

After written informed consent was obtained, participants completed the following: a demographic questionnaire; and modified Stanford Self-Efficacy Scale (4).

Modified Stanford Self-Efficacy Scale: The modified Stanford SelfEfficacy Scale is a six-item questionnaire adapted from self-efficacy scales developed for the Chronic Disease Self Management study as shown in Appendix 1. Self-efficacy refers to the patient's positive belief that she/he is equipped with the personal skills to achieve a successful health outcome (2). The scale contains several domains that are common across many chronic diseases, including: symptom control; role function; emotional functioning; and communication with physicians. The modified Stanford Self-Efficacy Scale has been validated in a large sample of 605 subjects with chronic diseases including breast cancer patients with a published mean $( \pm \mathrm{SD})$ of $5.2 \pm 2.2$ and an internal consistency of 0.91 (4).

\section{Interview framework}

Interviews were conducted with patients who had consented to a semistructured qualitative interview, and with six key health informants from various disciplines including a registered nurse, a nurse clinician, a case manager, a social worker, a radiation oncologist and a plastic surgeon. The semistructured interview guides used for both patients and key informants were designed to gather participant opinions on several fundamental themes including: perceived access to PMBR information; ideal timing for information delivery; preferred methods of information dissemination; and preferred content of PMBR information (Appendixes 2 and 3). Interviews were approximately $60 \mathrm{~min}$ in duration, and all were audiorecorded and transcribed verbatim by a professional transcription service.

\section{Data analysis}

Quantitative data: The modified Stanford Self-Efficacy Scale used in this study contained six items with scores from 1 to 10 for each item (4). Higher scores indicated higher patient perceived self-efficacy.

Qualitative data: Data from the in-depth and open-ended interviews were collected and analyzed in an iterative fashion, alternating between data collection and coding to generate a rich and dynamic understanding of the emerging content. Data analysis focused on domains and themes related to the following: patient perceptions of access to PMBR information; patient preference for ideal timing; patient preference for modes of delivery; patient preference for quantity; and patient preference for content of PMBR information. Open coding - the first step of the analytic process - involved generating initial codes and categories through a line-by-line analysis of a sample of interview transcripts. Initial categories were identified and coded by one reviewer experienced with the Grounded Theory Approach (5). Individual text fragments with a unique concept were given appropriate codes, and codes were subsequently grouped into overarching themes.

Data analysis: The independent variable in the present study was perceived self-efficacy. The dependent variables in the present study were the themes generated in the semistructured interviews. These included the following: perceived access to PMBR information; preference for ideal timing; preference for methods of delivery; preference for quantity; and preference for content of PMBR information. Themes were compared among the higher and lower self-efficacy patients to investigate differences in access to PMBR information, as well as differences in preferences for information delivery between the two groups with respect to timing, delivery method, quantity and content.

\section{RESULTS}

Participants

Ten women who met the inclusion criteria participated in the study. Three participants had already undergone PMBR, while seven participants were awaiting consultation for delayed PMBR. The responders ranged in age from 29 years to 75 years (median 47 years). Eight of the participants had obtained one or more university degrees, while two of the participants had completed their education at the high school level. Six of the 10 participants reported they had infrequently or never experienced financial difficulties. The median length of time from breast cancer diagnosis to the study was 11.5 months (Table 1).

\section{Self-efficacy scores}

The self-efficacy scores ranged from 5 to 9.3 (out of 10). The selfefficacy scores in this group of breast cancer patients were higher than the published mean $( \pm$ SD) of $5.2 \pm 2.2$ for a sample of 605 subjects with chronic diseases (4). Seven patients with scores above 7 out of 10 were categorized as having 'higher self-efficacy' and three patients with scores below 7 out of 10 were defined as having 'lower self-efficacy'. 


\section{Qualitative data}

After a descriptive thematic analysis of the semistructured interviews, two major themes were identified: initiation of the PMBR discussion; and perceived access to PMBR information.

\section{Initiation of the PMBR discussion}

Patient perspective: Six participants expressed that they did not feel well-equipped to initiate a conversation about PMBR. Five patients recalled that discussions of PMBR only began after they took proactive steps to initiate the conversation themselves. Self-efficacy levels did not predict patient's propensity for initiating the discourse on PMBR. Patients with both lower and higher self-efficacy expressed concern over the lack of a standardized process for initiating PMBR discussions.

The question "Had breast reconstruction ever come up as a topic with any of the members of the health care team?" elicited the following responses:

No, it never came up because my surgical oncologist basically said that they are looking at life expectancy and they look at the most minimally invasive procedure and of course he said lumpectomy and radiation was equivalent in survivor rates to mastectomy... and he just recommended that I have a lumpectomy... (patient 8, classified as lower self-efficacy).

Part of the problem is knowing what questions to ask and when you don't even know that you have cancer for sure at the beginning, you are not prepared to ask the right questions (patient 5 , classified as higher self-efficacy).

Key informant perspective: With the exception of the plastic surgeon, the other five key health informants believed that it was the members of the health care team that routinely initiated the discussion on PMBR. In addition, four key health informants consistently overestimated both the patients' knowledge about PMBR and their comfort level in initiating the discussion. A sample response to the question "In your experience, who usually initiates the conversation of breast reconstruction?" is as follows:

Breast cancer women - they are very motivated and information seekers... I think a lot women are coming to see their oncologist after they have done quite a bit research already. I think, in my experience is that if a woman doesn't bring up breast reconstruction, somewhere along the way the discussion probably gets introduced (social worker).

Thus, contrary to some of the patients' perspectives that selfadvocacy was needed to obtain a consultation with a plastic surgeon to discuss PMBR, five of the key health informants in our sample believed that a medical provider initiated the discourse on PMBR. Therefore, there appears to be a discrepancy in the perceptions between patients and health care providers with respect to who typically initiates the PMBR discussion.

Perceived access to PMBR information: The analysis in the present study demonstrates a lack of standardization in PMBR resources as perceived by patients. Six patients reported that accessible and credible information on PMBR was not made available to them. While five of the six key health informants believed that there was adequate availability of breast reconstruction resources, there was a mixed response with regard to patients' access to those resources. Four key health informants believed that the patients were well equipped to obtain reliable PMBR resources, while two believed that the patients needed more guidance to navigate through these materials. Within this overarching theme of access to PMBR information, patient preferences were further explored with respect to four individual subthemes: timing, modality, quantity and content of PMBR resources.

Timing: There was general agreement among all patients that early introduction to PMBR options was preferred. Another idea stated by some of the participants was the importance of having take-home resources, to allow for the review and understanding of information at their own pace. It was found that all three of the respondents who were categorized as having lower self-efficacy preferred repetition of information, whereas three of the seven participants categorized as having higher self-efficacy preferred to have all the information given to them at one time.

Modality: There was a great deal of variation among participants with regard to their preferred modality for PMBR information dissemination. The three main preferences that emerged were: an internet-based resource containing PMBR information specific to individual Canadian hospitals; a resource connecting mastectomy patients who have either already completed or are in the process of considering reconstruction; and visual aids such as before and after photos of PMBR, pictures of the implants, and a short video of various reconstructive surgeries. One notable difference between some participants who were classified as higher self-efficacy compared with lower self-efficacy was their preference for taking an active versus a passive role in information processing. All three of the responders with lower self-efficacy preferred a passive role in acquiring information in which a member of the health care team presented PMBR information to them face-to-face. In comparison, five of the responders who were classified as having higher self-efficacy preferred to take on a more active role, in which they sought out and then reviewed information on their own.

Quantity and content: Patients had variable preferences for the quantity and content of PMBR information, and no patterns of association were identified between those who were categorized as higher-self efficacy or lower self-efficacy. One unifying subtheme was that all patients wished to be educated on all potential PMBR options before making an informed surgical decision. Furthermore, six participants deemed that there was a lack of adequate information on postoperative care following PMBR. More specifically, patients wished for more information on the maintenance and surveillance of their reconstructed breasts, follow-up with their medical providers and long-term expectations of their reconstructed breast mounds.

\section{DISCUSSION}

Because PMBR is a completely elective procedure that can be performed at the same time as the mastectomy (immediate) or in a delayed fashion, its utilization varies widely - from $3.4 \%$ to $42 \%$ in North America $(6,7)$. These rates depend on multiple variables, including patient-, provider- and system-related factors $(6,7)$. One of the patient-related variables that may contribute to the utilization of PMBR is self-efficacy in obtaining access to PMBR information and consultation with a reconstructive surgeon. We have not been able to find evidence of self-efficacy being explored in this context in previous literature. Because recent decades have seen a paradigm shift away from paternalistic medicine to shared decision-making approaches, the joint participation of both physicians and patients is becoming more emphasized (8). Studies have shown that patients who are better informed are more likely to comply with treatment, are more satisfied and less anxious with their care, and have improved health outcomes (9-13). Intimately related to this idea of empowering patients to make complex decisions is the concept of self-efficacy. Self-efficacy refers to having positive beliefs about being equipped with the personal skills needed to achieve a successful health outcome (2). Higher self-efficacy in coping has been associated with better adjustment and a higher quality of life in patients with breast cancer (14-17).

Despite the relatively high scores for patient perceived self-efficacy in the present study, six of the participants did not feel well-equipped to initiate a conversation on PMBR with their health care team. In addition, patients' self-efficacy scores did not significantly correlate with their propensity to initiate the discussion on PMBR with their medical providers. Regardless of whether they were classified as having higher or lower self-efficacy, the responders in our study uniformly expressed their concern over the lack of a standardized process for educating patients about PMBR. An interesting finding that emerged was that while six of the 10 patients participating in our study said they did not feel that accessible and credible PMBR information was made available to them, four of the six key health informants that we interviewed believed that patients were well-equipped to seek out 
PMBR information and resources. Our results indicate that health care team members must be cautious in making an assumption that patient motivation equates to patient confidence in accessing information or initiating PMBR discussions. Provider reliance on self-efficacious women to actively seek out information on PMBR and self-refer for plastic surgery consultation is therefore presumptuous, and may pose as a barrier to PMBR. As a possible solution, tools such as a question prompt sheet to aid in the initiation of PMBR discussion and direct information exchange with every mastectomy consultation may help to both promote patient self-efficacy and develop stronger physicianpatient rapport (18).

Two novel findings emerged from the qualitative interviews. First, regardless of self-efficacy level, patients wished to hear about all the potential PMBR options early in their decision-making process. Second, while responders we classified as having lower self-efficacy preferred passive absorption of PMBR information, as in the case of a presentation by a member of the health care team, responders we classified as having higher self-efficacy preferred a more active role in independently gathering and processing information. These results are in keeping with previous findings that PMBR patients are a heterogeneous group of women who prefer different methods of information delivery (18). In their retrospective review of PMBR patients, Chen et al (19) also showed similar mixed preferences for information on breast reconstruction in which some participants preferred repetition whereas others preferred thorough one-time information sessions. In addition, consistent with our findings, other studies have demonstrated that in patients with lower self-efficacy, those with the highest breast cancer knowledge were women whose physicians provided them with greater emotional support (19). These findings underscore the importance of identifying patients with lower self-perceived efficacy, to provide more hands-on support and face-to-face discussions to strengthen their decision-making capacity.

The major weakness of the present study is the small sample size of 10 patients and six key health informants. The themes and ideas expressed by this subset of patient responders and key health professional informants are limited and, therefore, cannot be extrapolated to all patient populations at different breast cancer treatment centres. Nevertheless, the findings were helpful in revealing part of the patient and health provider perspective on access to PMBR information, as well as how self-efficacy may affect patient preferences in PMBR information dissemination. This warrants further study with a larger adequately powered sample size. Other limitations include possible sampling bias of only those patients who are either considering or have undergone PMBR, because this subset of patients may represent a higher self-efficacy group. However, despite the possible selection bias of our participants, we still found that the majority of our participants felt a lack of confidence in initiating PMBR discussions and obtaining adequate informational resources. Extrapolating from this finding, it is conceivable that underserved populations with lower overall selfefficacy scores may not have accessibility to PMBR at all, as observed by Maly et al (3).

\section{CONCLUSION}

Health care providers should be more cognizant of imposing assumptions of patient self-efficacy and, instead, assume more responsibility in standardizing information dissemination on PMBR that should be distributed early in the breast cancer journey. Furthermore, information on PMBR should be complete and standardized, with patients being educated on all available options, recognizing that these themes and conclusions should be further investigated with larger numbers of participants over a longer period of time. Finally, we may be able to help patients make more medically sound and personally satisfying decisions regarding PMBR by tailoring the delivery of information to the patient's self-efficacy level.

ACKNOWLEDGEMENTS: The authors thank the Determinants of Community Health Program in the Faculty of Medicine at University of Toronto and the Breast Cancer Survivorship Program for supporting this research.

APPENDIX 1

MODIFIED STANFORD SELF-EFFICACY FOR
MANAGING CHRONIC DISEASE 6-ITEM SCALE

We would like to know how confident you are in doing certain activities. For each of the following questions, please choose the number that corresponds to your confidence that you can do the tasks regularly at the present time.

1. How confident are you that you can keep the fatigue caused by your disease from interfering with the things you want to do?

Not at all confident $\begin{array}{llllllllll}1 & 2 & 3 & 4 & 5 & 6 & 7 & 8 & 9 & 10 \text { Totally confident }\end{array}$

2 . How confident are you that you can keep the physical discomfort or pain of your disease from interfering with the things you want to do?

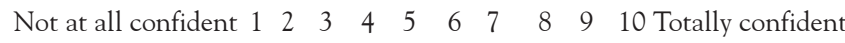

3. How confident are you that you can keep the emotional distress caused by your disease from interfering with the things you want to do?

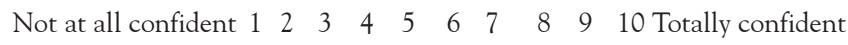

4. How confident are you that you can keep any other symptoms or health problems you have from interfering with the things you want to do?

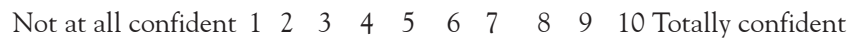

5. How confident are you that you can do the different tasks and activities needed to manage your health condition so as to reduce your need to see a doctor?

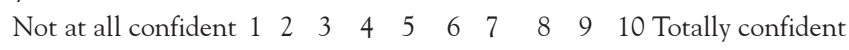

6. How confident are you that you can do things other than just taking medication to reduce how much your illness affects your everyday life?

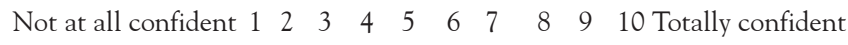

\section{APPENDIX 2 \\ SEMI-STRUCTURED INTERVIEW FOR KEY HEALTH CARE PROVIDER INFORMANTS}

\section{Access}

What do you perceive to be the current barriers to access to breast reconstruction information at $\mathrm{PMH}$ ?

(If they do not mention self-efficacy)

Do you believe lack of self-efficacy may be a significant barrier to their access? Self-efficacy is defined as one's confidence in his or her ability to take action.

Have you had any experiences where patients have expressed their difficulty in accessing information about breast reconstruction?

Information needs

Do you have any suggestions as to how information regarding breast reconstruction could be ideally disseminated to mastectomy patients?

a) Any suggestions for what content should be included about breast reconstruction?

b) Any suggestions for what methods of delivery of information might be most effective for the patients?

c) Any suggestions for when the most appropriate time might be to deliver breast reconstruction information?

\section{APPENDIX 3 \\ SEMI-STRUCTURED INTERVIEW FOR MASTECTOMY PATIENTS (RECRUITED FROM BREAST RECONSTRUCTION CONSULTATIONS AT TORONTO GENERAL HOSPITAL)}

Part 1: Information about the cancer diagnosis

How long ago did you receive your diagnosis of cancer? 
And at what stage was your cancer when you were diagnosed?

How about the grade of your cancer?

What kinds of treatments have you had or plan on having for your breast cancer?

(chemotherapy, radiation, hormone therapy, surgery)

Have you had your mastectomy surgery?

If Yes - Have you had your breast reconstruction surgery yet?

If No - Are you considering the combined surgery with both mastectomy and breast reconstruction at once?

Just to clarify:

a) Did you have a consult at the BCSP with Scott? And did you receive the breast reconstruction information pamphlet from him?

b) Did you have the reconstruction consultation with a plastic surgeon at TGH? And was that with Dr Zhong or Dr Hofer?

\section{Part 2: Access to information}

And when was it that you first considered breast reconstruction? Did you start thinking about breast reconstruction before or after your mastectomy?

Before your consultation with Scott/Dr Zhong/Dr Hofer, were you able to find out any information about breast reconstruction surgery?

Please describe:

(How did you get that information - did a member of your health care team bring up the topic or did you bring up the topic?)

(In what format did you receive the information? - a pamphlet, a clinical discussion with a doctor or nurse, etc...)

Did you experience any difficulties accessing information about breast reconstruction? Please describe:

Were you uncomfortable or awkward to bring up the question? Please describe:

\section{Part 3: Preferences for information}

*Let the patient know that there are three separate sections in this part of the interview to discuss the appropriate time to deliver information, method of delivery of information, and the content of the information (to reduce repetition of responses).*

Appropriate time to deliver information

Did you feel that the timing of the initial survivorship consult when Scott gave you the breast reconstruction information pamphlet/ reconstruction consultation with Dr Zhong/Dr Hofer was appropriate for you?

When would you suggest is the best time during your care for breast reconstruction to be brought up to you?

When would you suggest is the best time for more detailed information about breast reconstruction be given to you or discussed with you?

(During surgery appointment, Breast cancer consultation with the BCSP or consultation with a plastic surgeon)

*the following are more detailed suggestions to encourage the patient to give more specific answers to the above question*

- Facts presented on same day as diagnosis and treatment plan?

- Staggered so limited facts presented first, perhaps before the mastectomy, with the offer of more detailed information at later appointments?

- Option of receiving all details/in-depth information at your first appointment?

Do you feel that receiving the information once is enough? Or would repetition of the information be beneficial?

(When should the information be repeated?)

- Maybe have some resources like booklets or online information - so that those wanted more details could have access?
Methods of providing information

Only ask the following two questions if patient was recruited from breast reconstruction consultations at $\mathrm{TGH}$ :

Did you feel that the verbal one-on-one consultation with Dr Zhong/ Dr Hofer was an appropriate way of learning about reconstruction for you?

Can you think of anything that could have been improved during the consultation?

(Examples: given more chances to ask questions, given more time to absorb and understand information)

Did you have a chance to look at the information pamphlet Scott/ Dr Zhong/Dr Hofer gave you? Did you find that having a pamphlet to read and refer to was helpful?

Can you think of anything that could have been improved about the pamphlet?

Would another method of providing information have been more beneficial to you?

(Examples to prompt the patient if needed):

- Verbal group session

- Written pamphlet

- Audiovisual methods (eg, Videos)

Do you think you might have liked to have information presented to you in more than one way?

\section{Content of information}

Did you feel that there was any information that was left out of the consultation/the booklet that you would've wanted to know about?

Only ask the following question if the patient was recruited from breast reconstruction consultations at TGH:

Can you think of any topics Dr Zhong/Dr Hofer talked about that you might have wanted to spend more time on?

Can you think of any topics in the information pamphlet that you would have liked to be explained more in depth?

(Information about who is eligible for breast reconstruction, options for when to begin reconstruction, and different option for methods of reconstruction along with their safety and result expectations will definitely be information that would be relayed to mastectomy patients.)

Can you pick 5 out of the following 12 topics that you feel would be most important for you to learn about: (mark down on paper)

- How long the entire process of reconstruction and healing is

- What your breasts might look like after surgery - realistic expectations

- What is sensation in the breasts like after breast reconstruction

- What the potential pain and discomfort is like, and how to manage it

- Stressing the complications that could happen from reconstructive surgery

- More details about the implants (risks, management)

- The potential for nipple removal during breast reconstruction surgery

- What are some good options of bras and swimwear for reconstructed breasts

- How would you care for your reconstructed breasts (massage, skin products)

- What kinds of follow-up procedures would you have to do after the reconstruction surgery

- What happens immediately postoperatively after the breast reconstruction surgery (recovery in hospital, how do breasts feel)

- Things that might help to psychologically prepare you for the breast reconstruction 


\section{REFERENCES}

1. Cancer Support Community. New survey finds nearly half of breast cancer patients do not receive information about reconstruction options at diagnosis. Washington DC, Cancer Support Commnunity, 2010.

2. Bandura A. Self-efficacy: The exercise of control. New York: Freeman, 1997.

3. Maly RC, Liu Y, Kwong E, et al. Breast reconstructive surgery in medically underserved women with breast cancer: The role of patient-physician communication. Cancer 2009;115:4819-27.

4. Lorig KR, Sobel D, Ritter PL, et al. Effect of a self-management program for patients with chronic disease. Eff Clin Pract 2001;4:256-62.

5. Lam WWT, Fielding R. Is self-efficacy a predictor of short-term post-surgical adjustment among Chinese women with breast cancer? Psycho-Oncology 2007;16:651-9.

6. Platt J, Baxter N, Zhong T. Breast reconstruction after mastectomy for breast cancer. CMAJ 2011;183:2109-16.

7. Alderman AK, Hawley ST, Waljee J, et al. Correlates of referral practices of general surgeons to plastic surgeons for mastectomy reconstruction. Cancer 2007;109:1715-20.

8. Charles C, Gafni A, Whelan T. Decision-making in the physicianpatient encounter: Revisiting the shared treatment decision-making model. Soc Sci Med 1999;49:651-61.

9. Roter DL, Hall JA, Merisca R, et al. Effectiveness of interventions to improve patient compliance: A meta-analysis. Med Care 1998;36:1138-61.

10. Bertakis KD. The communication of information from physician to patient: a method for increasing patient retention and satisfaction. J Fam Pract 1977;5:217-22.
11. Morris J, Royle GT. Offering patients a choice of surgery for early breast cancer: A reduction in anxiety and depression in patients and their husbands. Soc Sci Med 1988;26:583-5.

12. Greenfield S, Kaplan S, Ware JE Jr. Expanding patient involvement in care. Effects on patient outcomes. Ann Intern Med 1985;102:520-8.

13. Kaplan SH, Greenfield S, Ware JE Jr. Assessing the effects of physician-patient interactions on the outcomes of chronic disease. Med Care 1989;27:S110-27.

14. Arora NK, Johnson P, Gustafson DH, et al. Barriers to information access, perceived health competence, and psychosocial health outcomes: Test of a mediation model in a breast cancer sample. Patient Educ Couns 2002; 47:37-46.

15. Beckham JC, Burker EJ, Lytle BL, et al. Self-efficacy and adjustment in cancer patients: A preliminary report. Behav Med 1997;23:138-42.

16. Graves KD. Social cognitive theory and cancer patients' quality of life: A meta-analysis of psychosocial intervention components. Health Psychol 2003;22:210-9.

17. Lev Elise L, Paul D, Owen Steven V. Age, self-efficacy, and change in patients' adjustment to cancer. Cancer Practice 1999;7:170-6.

18. Brown RF, Butow PN, Dunn SM, et al. Promoting patient participation and shortening cancer consultations: A randomised trial. Br J Cancer 2001;85:1273-9.

19. Chen JY, Diamant AL, Thind A, et al. Determinants of breast cancer knowledge among newly diagnosed, low-income, medically underserved women with breast cancer. Cancer 2008;112:1153-61. 